\title{
Camallanus cotti (Nematoda: Camallanidae), an introduced parasite of fishes in New Caledonia
}

\author{
František Moravec $^{1}$ and Jean-Lou Justine ${ }^{2}$
}

${ }^{1}$ Institute of Parasitology, Biology Centre, Academy of Sciences of the Czech Republic, Branišovská 31, 37005 České Budějovice, Czech Republic;

${ }^{2}$ Équipe Biogéographie Marine Tropicale, Unité Systématique, Adaptation, Évolution (UPMC, CNRS, MNHN, IRD), Institut de Recherche pour le Développement, BP A5, 98848 Nouméa Cedex, New Caledonia

Key words: parasitic nematode, Camallanus cotti, introduced species, Awaous, Kuhlia, New Caledonia, South Pacific

\begin{abstract}
A pathogenic Asian nematode species of Camallanus, C. cotti Fujita, 1927, was found in New Caledonia, South Pacific, for the first time; it was recorded from two native fishes, Awaous guamensis (Valenciennes) (Gobiidae) (prevalence 51\%, intensity 1-25) and Kuhlia marginata (Cuvier) (Kuhliidae) (a single specimen found), of the La Foa River, about $100 \mathrm{~km}$ north of Nouméa; the latter represents a new host record. Morphological data on C. cotti based on New Caledonian specimens and those previously collected from aquarium-kept Misgurnus anguillicaudatus (Cantor) in Canada have been provided. The SEM examination of $C$. cotti, applied for the first time in this species, made it possible to study some of its morphological details; firststage larvae from the female's uterus were found to possess several digit-like processes on the tail tip, not previously reported for any species of the Camallanidae. Camallanus moraveci Petter, Cassone et France, 1974 is considered a junior synonym of $C$. cotti. A list of hitherto recorded hosts of $C$. cotti is provided. Camallanus cotti is assumed to be introduced into New Caledonia along with the introduction of the exotic poeciliid fishes, which are known to be among the most common hosts of $C$. cotti in aquarium cultures worldwide.
\end{abstract}

New Caledonia is an interesting area from the zoogeographical point of view, with a high degree of endemism. Despite this fact, almost no attention has been paid to the parasites of native fishes in freshwater habitats. Regarding parasitic nematodes, the only paper is that recently published by Moravec et al. (2006a), dealing with a new species of Procamallanus Baylis, 1923 from Pacific eels (Anguilla spp.) in freshwater bodies, including those in northern New Caledonia.

Gargominy et al. (1996) mentioned a total of 800 flowering plants, at least 400 invertebrates and 36 vertebrates now established in the wild in New Caledonia. This includes several species of freshwater fishes (Marquet et al. 2003) introduced into New Caledonian streams from different continents. However, along with the introduction of fishes, also their parasites are often introduced, which may subsequently endanger the native fish populations, as pointed out, e.g., by Font and Tate (1994) and Font (1997a, b) in Hawaii. Therefore, studies of parasites of New Caledonian freshwater fishes and their inventories are highly needed.

In September of 2004, a sample of fishes was collected from the La Foa River near La Foa, northern New Caledonia, where two native fish species were found to be infected with the apparently introduced nematode Camallanus cotti Fujita, 1927, a pathogenic parasite of many fish species introduced from East Asia to many countries of different continents. Although $C$. cotti has several times been described, there are still some problems concerning its morphology, taxonomy and life cycle. Moreover, this species has not previously been studied using scanning electron microscopy (SEM). The purpose of this paper is to treat this parasite on the basis of New Caledonian material, with the use of previously unpublished results by the senior author (F.M.) based on specimens from aquarium-kept Misgurnus anguillicaudatus (Cantor) in Canada.

\section{MATERIALS AND METHODS}

Fishes were caught by electrofishing in the La Foa River near La Foa, northern New Caledonia on 23 September 2004. They were transported alive to the IRD laboratory in Nouméa and immediately examined for the presence of helminth parasites. The following fish species were collected and examined (the introduced species are marked with an asterisk): Anguillidae: giant mottled eel Anguilla marmorata Quoy et Gairmard $(\mathrm{n}=2)$ and speckled longfin eel Anguilla reinhardtii Steindachner ( $\mathrm{n}=11$ ); Cichlidae: Mozambique tilapia *Oreochromis mossambicus (Peters) $(\mathrm{n}=1)$; Gobiidae: Awaous guamensis (Valenciennes) $(\mathrm{n}=35)$, speckled goby Redigobius bikolanus (Herre) $(\mathrm{n}=1)$ and bichique Sicyopterus lagocephalus (Pallas) $(\mathrm{n}=1)$; Kuhliidae: dark-margined flagtail Kuhlia marginata (Cuvier) $(\mathrm{n}=2)$ and Kuhlia rupestris (Lacépède) (n =2); Mugilidae: flathead mullet Mugil cephalus Linnaeus $(\mathrm{n}=$ 4) and (?) otomebora mullet Liza melinoptera (Valenciennes) $(\mathrm{n}=1)$; Poeciliidae: green swordtail ${ }^{*}$ Xiphophorus helleri Heckel $(\mathrm{n}=3)$. Of them, only A. guamensis and K. marginata 
harboured the nematodes. The nematodes for morphological studies were fixed in hot $4 \%$ formaldehyde solution. For light microscopical examination, nematodes were cleared with glycerol. Drawings were made with the aid of a Zeiss microscope drawing attachment. Specimens used for SEM were postfixed in $1 \%$ osmium tetroxide, dehydrated through a graded ethanol series, critical point dried and sputter-coated with gold; they were examined using a JEOL JSM-6300 scanning electron microscope at an accelerating voltage of $15 \mathrm{kV}$. Caudal ends of the nematode first-stage larvae were studied in broken female specimens. Specimens of Camallanus cotti from aquarium-kept Misgurnus anguillicaudatus (Cobitidae) in Canada (Nanaimo, British Columbia), provided by Dr. N.P. Boyce, were examined during the senior author's (F.M.) stay at the Pacific Biological Station in Nanaimo, BC in the spring 1979 and were deposited there in the parasite collection. It is unknown where the aquarium-kept $M$. anguillicaudatus was caught and which fish species it may have been kept with. For comparative purposes, voucher specimens of $C$. cotti from the material of Rigby et al. (1997) collected from Awaous guamensis, Poecilia reticulata, Xiphophorus helleri and Lentipes concolor of the Hakalau Stream, Hawaii and from an aquarium-kept Potamotrygon sp., now deposited in the US National Parasite Collection (USNPC Nos. 86994, 86995, 86997, 87002, 87004, 87005, 87062), were examined. All measurements are in micrometres $(\mu \mathrm{m})$ unless otherwise stated. Fish names follow FishBase (Froese and Pauly 2006).

\section{RESULTS}

Camallanus cotti Fujita, 1927

Figs. 1-5

Syns.: Camallanus zacconis Li, 1941; C. fotedari Raina et Dhar, 1972; C. moraveci Petter, Cassone et France, 1974.

Description (based on specimens from Awaous guamensis): Medium-sized nematodes with finely transversely striated cuticle and large orange-brown buccal capsule typical of genus. Mouth aperture slitshaped, surrounded by four submedian cephalic papillae and two lateral amphids. Valves of capsule roughly pentagonal in lateral view, internally bearing smooth longitudinal ridges, some incomplete. Anterior outer surface of each valve with two longitudinally elongate sclerotized plates. Narrow, sclerotized ring present at bottom of capsule. Tridents large, only moderately surpassing posterior border of buccal capsule. Excretory pore somewhat posterior to level of nerve ring. Deirids small, slightly asymmetrical, located at about two thirds of muscular oesophagus.

Male (5 specimens): Length of body $2.60-3.63 \mathrm{~mm}$, maximum width 163-231. Buccal capsule including basal ring 96-105 long, maximum width 87-93; size of basal ring $12 \times 57-66$; length of tridents 66-81. Each valve of capsule internally with 14-18 longitudinal ridges, 3-8 incomplete. Muscular oesophagus 340-381 long, 63-78 wide; glandular oesophagus 367-517 long, 66-87 wide; length ratio of both parts of oesophagus 1:1.08-1.36. Buccal capsule and oesophagus represent- ing $25-31 \%$ of total body length. Nerve ring, excretory pore and deirids 174-195, 222-246 and 291-321, respectively, from anterior extremity. Posterior end of body with vesiculate caudal alae. Pedunculate papillae: 7 pairs preanal and 6 pairs postanal; papillae of first preanal pair situated somewhat anterior to anterior ends of caudal alae (Figs. 1 H,I, 2 D,I), postanal papillae of first three pairs close together (Figs. $1 \mathrm{~K}, 2 \mathrm{E}$ ). Cloacal aperture surrounded by 2 pairs of transverse sessile papillae. Spicules unequal, simple; length of larger (right) spicule 141-156, of smaller (left), less sclerotized spicule 81-132; length ratio of spicules 1:1.071.93. Length of tail 90-111.

Female (5 gravid specimens; measurements of 1 subgravid specimen in parentheses): Body length of specimens with larvae in uterus 7.00-9.44 (6.62) mm, maximum width 367-490 (286). Buccal capsule including basal ring 147-174 (153) long, maximum width 129-150 (141); basal ring 18 (18) long, 81-90 (81) wide; length of tridents 135-156 (141). Each valve of capsule with 21-22 (21) ridges, 5-7 (5) incomplete. Muscular oesophagus 517-653 (530) long, 105-117 (102) wide; glandular oesophagus 571-666 (571) long, 99-111 (108) wide; length ratio of both parts of oesophagus 1:1.09-1.29 (1:1.08). Buccal capsule and oesophagus representing 15-19 (19) \% of total body length. Nerve ring, excretory pore and deirids 249-286 (252), 297-375 (291) and 411-557 (402), respectively, from anterior extremity. Tail very elongate, 1.27-1.39 (1.12) mm long, representing 12-18 (17) \% of body length, with rounded tip without any processes. Posterior lip of anus with characteristic dotted sculpture (Fig. $2 \mathrm{~J})$. Vulva slightly postequatorial (preequatorial), 3.60$5.15(3.17) \mathrm{mm}$ from anterior end of body [at 51-55 (48) \% of body length], with somewhat elevated lips. Vagina muscular, directed posteriorly from vulva. Uterus extending posteriorly into tail, filled with numerous larvae.

Female fourth-stage larva (1 specimen from Kuhlia marginata): Body length $1.55 \mathrm{~mm}$, maximum width 117. Four cephalic papillae present. Buccal capsule including basal ring 69 long, 57 maximum wide; basal ring 6 long, 39 wide; tridents absent. Each valve of capsule externally with small median transverse sclerotized plate (anlage of two cephalic sclerotized plates in adults) on anterior end and internally with 12 longitudinal ridges, 3 incomplete. Muscular oesophagus 285 long, 45 wide; glandular oesophagus 264 long, 45 wide; length ratio of both parts of oesophagus 1:0.93. Buccal capsule and oesophagus representing $40 \%$ of total body length. Nerve ring and excretory pore 135 and 165, respectively, from anterior extremity. Deirids not found. Small, oval genital primordium situated ventrally 1.01 $\mathrm{mm}$ from anterior extremity (at $65 \%$ of body length). Tail conical, 162 long, with 3 small conical cuticular spikes on tip; spikes 3 long. 

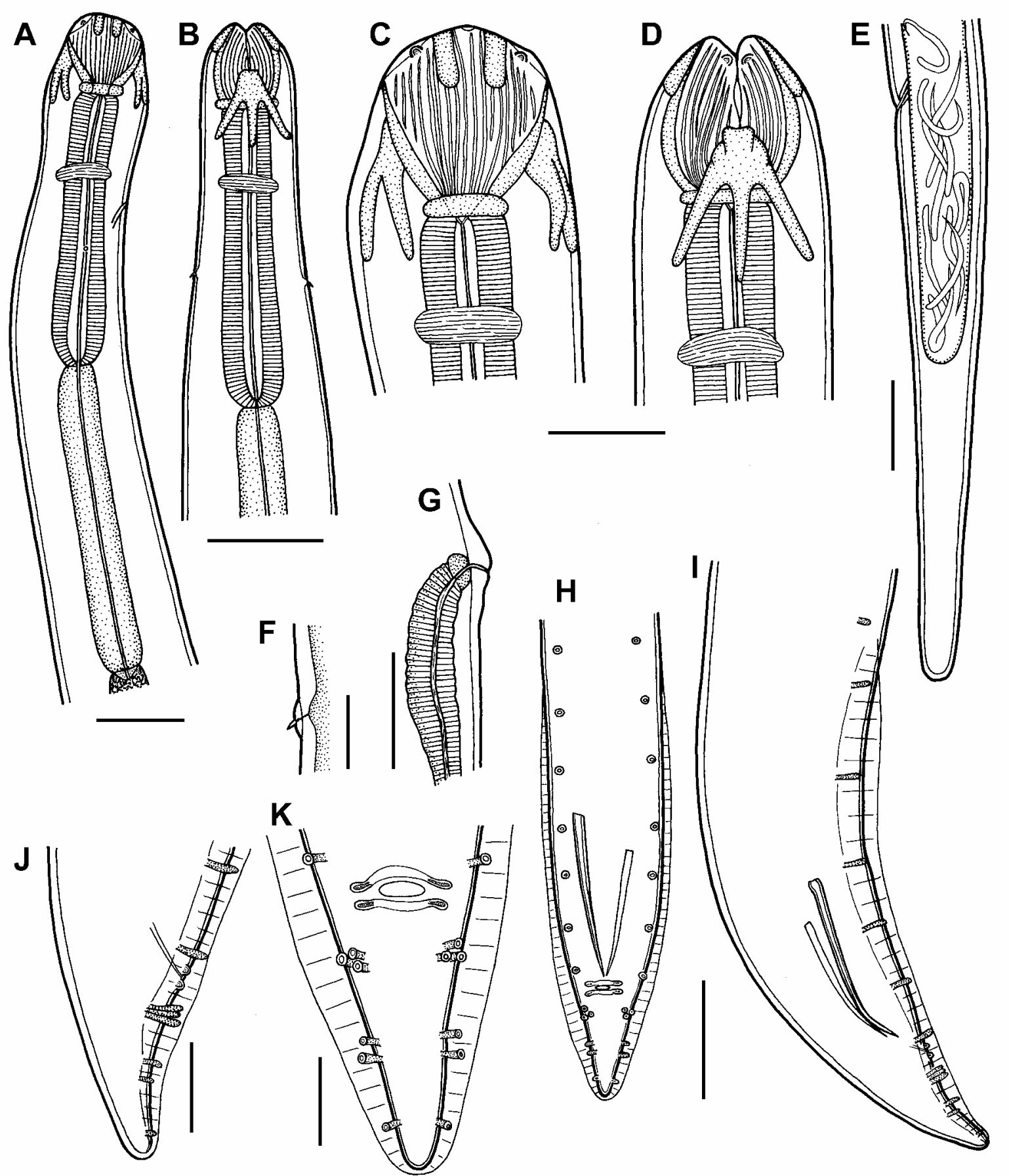

Fig. 1. Camallanus cotti Fujita, 1927, adults from Awaous guamensis, New Caledonia. A, B - anterior end of gravid female, lateral and dorsoventral views; C, D - buccal capsule, lateral and dorsoventral views; $\mathbf{E}$ - tail of gravid female, lateral view; $\mathbf{F}$ deirid, lateral view; $\mathbf{G}$ - vulva, lateral view; $\mathbf{H}, \mathbf{I}$ - posterior end of male, ventral and lateral views; $\mathbf{J}, \mathbf{K}$ - tail of male, lateral and ventral views. Scale bars: A, B, E = $200 \mu \mathrm{m} ; \mathrm{C}, \mathrm{D}, \mathrm{G}-\mathrm{I}=100 \mu \mathrm{m} ; \mathrm{F}=20 \mu \mathrm{m} ; \mathrm{J}=50 \mu \mathrm{m} ; \mathrm{K}=30 \mu \mathrm{m}$.

H o s t s : Awaous guamensis (Gobiidae) (body length 66-145 $\mathrm{mm}$ ) [adults and fourth-stage larvae] and dark-margined flagtail Kuhlia marginata (Kuhliidae) (body length $62 \mathrm{~mm}$ ) (both Perciformes) [fourth-stage larva].

Site of infection: Intestine.

L o c a 1 it y: La Foa River, La Foa, northern New Caledonia (collected 23 September 2004).
Prevale n ce and inten s it y: A. guamensis: $51 \%$ (18 fish infected / 35 fish examined); 1-25 (mean 5) nematodes per fish. K. marginata: $1 / 1 ; 1$.

Deposition of voucher specimens: Muséum National d'Histoire Naturelle, Paris (Cat. Nos. JNC13081330) and Institute of Parasitology, Biology Centre, ASCR, České Budějovice (Cat. No. N-11). 


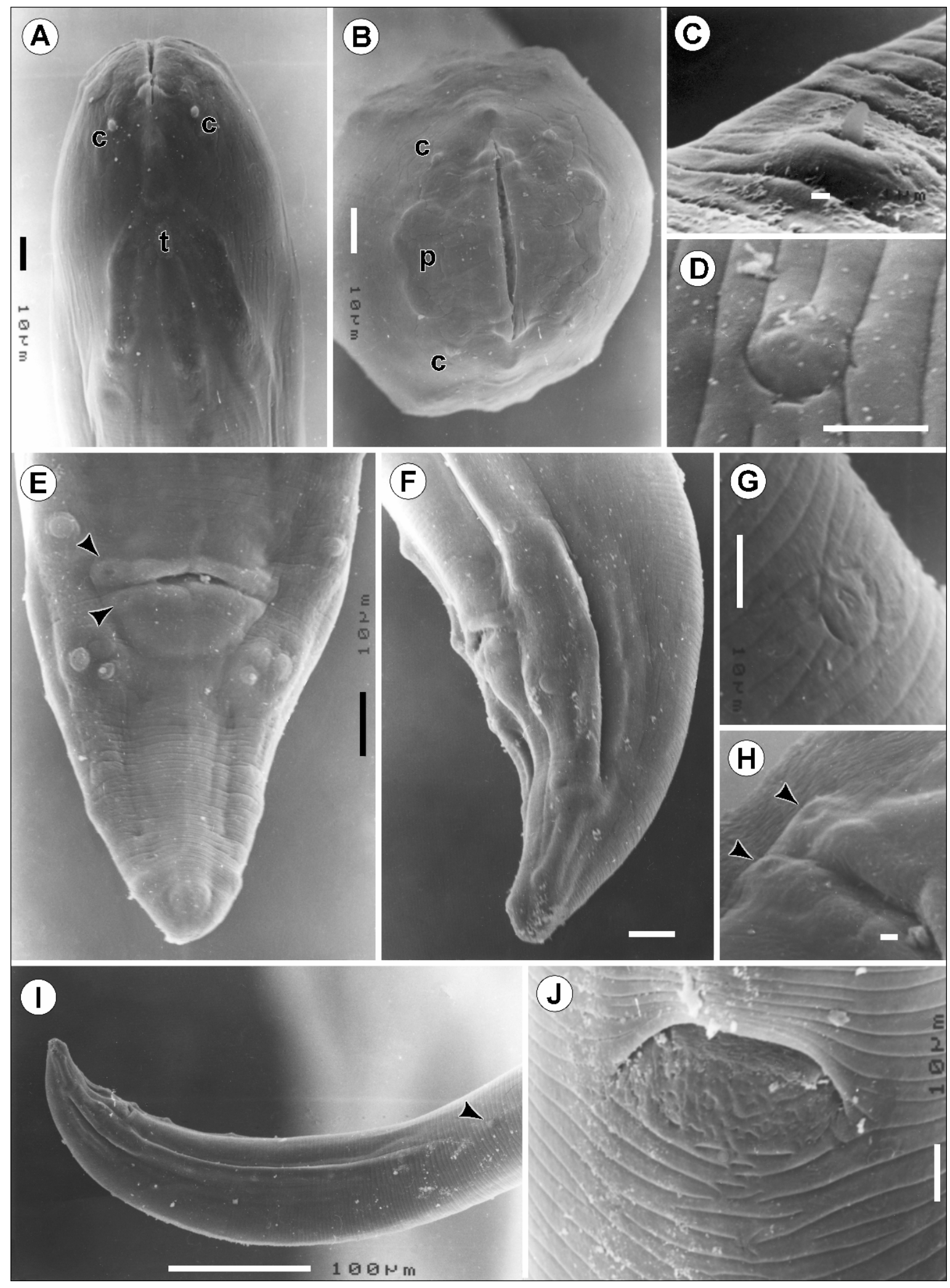

Fig. 2. Camallanus cotti Fujita, 1927 from Awaous guamensis, scanning electron micrographs of adults. A, B - cephalic end, dorsoventral and apical views; C - deirid; D - papilla of first preanal pair; E, F - tail of male, ventral and lateral views (arrowheads show circumcloacal papillae); $\mathbf{G}$ - phasmid on female tail; $\mathbf{H}$ - detail of cloacal aperture and circumcloacal papillae (arrowheads); I - posterior end of male, lateral view (arrowhead shows first preanal papilla situated anterior to caudal ala); $\mathbf{J}$ - anal opening of female (note structure of posterior anal lip). Abbreviations: $\mathrm{c}$ - cephalic papilla; $\mathrm{p}$ - sclerotized plate of buccal capsule; $\mathrm{t}$ - trident. Scale bars: $\mathrm{C}, \mathrm{H}=1 \mu \mathrm{m} ; \mathrm{D}=5 \mu \mathrm{m} ; \mathrm{F}=10 \mu \mathrm{m}$. 

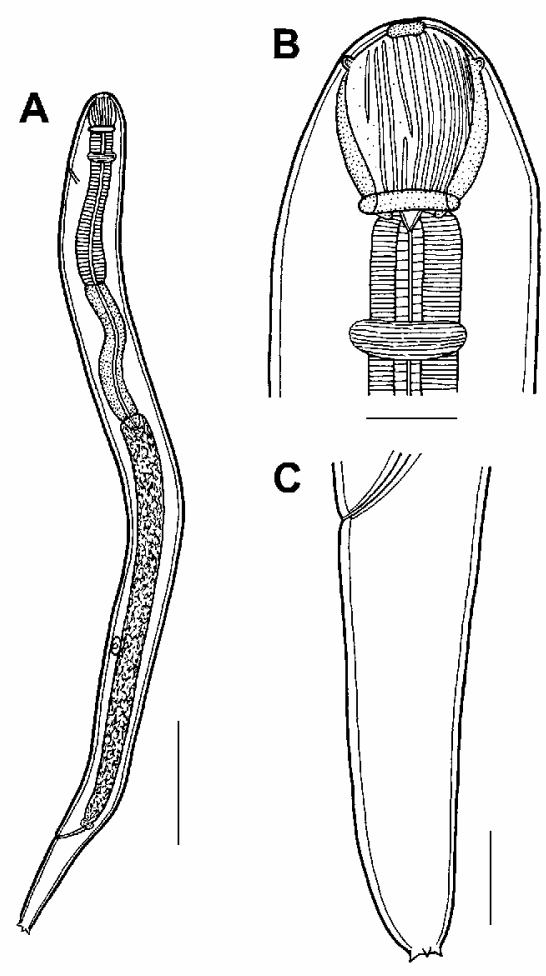

Fig. 3. Camallanus cotti Fujita, 1927, fourth-stage larva from Kuhlia marginata, New Caledonia. A - general view; B anterior end, lateral view; $\mathbf{C}$ - tail, lateral view. Scale bars: A $=200 \mu \mathrm{m} ; \mathrm{B}, \mathrm{C}=30 \mu \mathrm{m}$.

\section{Measurements of Camallanus cotti from aquarium- kept Misgurnus anguillicaudatus in Nanaimo, British Columbia, Canada}

Male (7 specimens): Body length 1.84-3.04 mm, maximum width 93-167. Buccal capsule including basal ring 69-87 long, 69-81 maximum wide. Basal ring 7-9 long, 46-51 wide. Each valve of capsule with 15-17 ridges. Length of tridents $69-83$. Length of muscular oesophagus 235-294, of glandular oesophagus 290-460. Nerve ring and excretory pore 140-184 and 161-317, respectively from anterior extremity. Deirids not located. Pedunculate subventral papillae: 7 pairs preanal and 6 pairs postanal; 2 pairs of sessile ventral papillae surrounding cloacal aperture. Larger (right) spicule 115-150 long, smaller (left), less sclerotized spicule 92-110 long. Length of tail 92-108.

Female (3 gravid specimens; measurements of 3 juvenile specimens in parentheses): Body length of larvigerous specimens $7.92-8.84 \mathrm{~mm}$ (juvenile specimens 2.02-4.32), maximum width 279-326 (112-186). Buccal capsule including basal ring 120-143 (81-122), 133-138 (94-115) maximum wide. Basal ring 12-14 (7-12) long, 64-76 (57-81 wide. Each valve of capsule with 16-18 (15-17) ridges. Length of tridents 97-108 (76-108). Length of muscular oesophagus 428-437 (253-469), of glandular oesophagus 644-736 (258391). Nerve ring 230-235 (184-267) from anterior extremity; excretory pore and deirids not located. Vulva
$4.01-4.40 \mathrm{~mm}$ from anterior extremity (at $47-56 \%$ of body length). Tail 1.32-1.61 mm (294-902) long, forming 17-18 (15-21) \% of body length.

Fourth-stage larva (2 specimens): Body length 0.90$1.94 \mathrm{~mm}$, maximum width 65-93. Buccal capsule including basal ring 41-64 long, 44-53 wide. Basal ring 5-7 long, 30-37 wide. Each valve of capsule with 1517 ridges. Tridents absent. Length of muscular oesophagus 152-230, of glandular oesophagus 138-276. Nerve ring and excretory pore 87-136 and 145-207, respectively, from anterior extremity. Deirids not found. Tail 124-207 long, forming 11-14\% of body length, with three minute spikes on tip.

\section{DISCUSSION}

The morphology and measurements of New Caledonian specimens correspond, more or less, to C. cotti, as it has been redescribed by Moravec and Nagasawa (1989) from the type locality in Japan and by Moravec and Sey (1988) and Moravec et al. (2003) from fishes in Vietnam and China, respectively. Unlike the abovementioned authors and previous data by Fujita (1927a,b) and Yamaguti (1935, 1941), Rigby et al. (1997), in $C$. cotti specimens from Poecilia reticulata (Peters) introduced into Hawaii, illustrated the tridents of the buccal capsule reaching to the level of the nerve ring, caudal alae joining anteriorly, and the larger spicule as the left one (generally in camallanids the longer spicule is on the right side); according to Moravec et al. (2003), it could not be excluded that, in fact, they dealt with a different species. However, a recent reexamination of their voucher specimens showed that the morphology of the Hawaii specimens does not differ from that of $C$. cotti in other regions. The SEM examination, applied in this species for the first time, confirmed the presence of small deirids (Fig. 2 C) and caudal alae not joining anteriorly (Fig. 2 I). It showed that, in contrast to some other Camallanus spp. studied by SEM (e.g., Moravec et al. 2006b), the female posterior anal lip had a characteristic sculpture (Fig. $2 \mathrm{~J}$ ) and that the first pair of preanal papillae in male may be situated anterior to caudal alae (Fig. 2 D, I).

A SEM examination of the first-stage larvae from the C. cotti female's uterus revealed that their tail tip was provided with a crown of several minute digit-like processes (Fig. 5), not previously reported for any species of Camallanus. They are almost invisible under the light microscope. Although the first-stage larva of Camallanus oxycephalus Ward et Magath, 1916 was studied by SEM (Kelly et al. 1989), no such caudal processes were found; on the contrary, similar processes were found by SEM in the larvae of this stage in Camallanus lacustris (Zoega, 1776) (Drábek and Moravec, unpublished) (Fig. 6). Apparently, these caudal processes serve the larva to the better attachment by its tail to the bottom, after the larvae are released into the water; the larvae attach themselves to the bottom by their tails and 


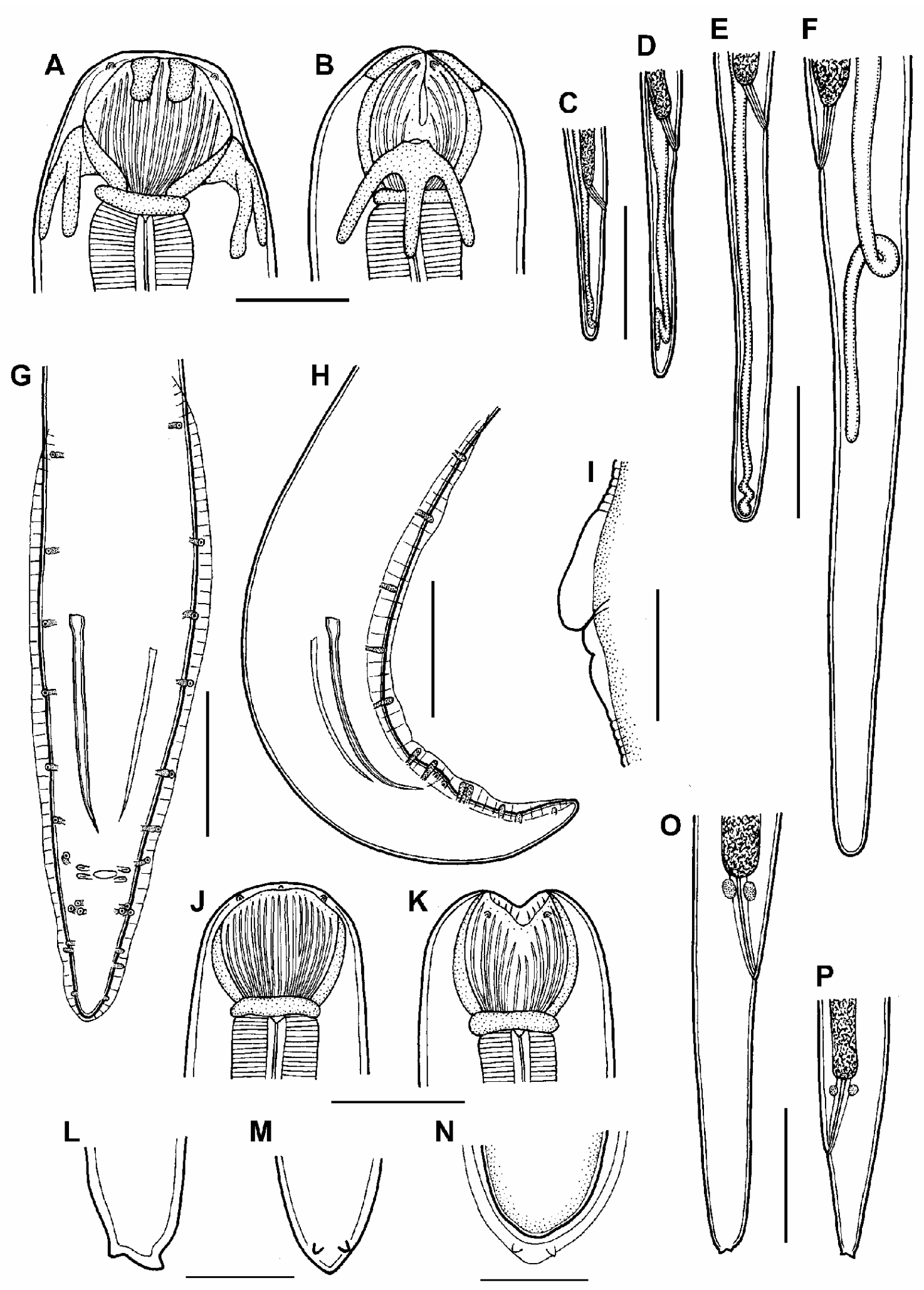

Fig. 4. Camallanus cotti Fujita, 1927, adults and fourth-stage larvae from aquarium-reared Misgurnus anguillicaudatus, Canada. A, B - buccal capsule of gravid female, lateral and dorsoventral views; $\mathbf{C}-\mathbf{F}$ - development of tail in female $(\mathbf{C}-$ young specimen with body length $2.02 \mathrm{~mm}, \mathbf{D}$ - with body length $2.84 \mathrm{~mm}, \mathbf{E}$ - with body length $4.32 \mathrm{~mm}, \mathbf{F}$ - gravid specimen $7.92 \mathrm{~mm}$ long); $\mathbf{G}, \mathbf{H}$ - posterior end of male, ventral and lateral views; $\mathbf{I}$ - vulva, lateral view; $\mathbf{J}, \mathbf{K}$ - buccal capsule of fourth-stage larva, lateral and dorsoventral views; $\mathbf{L}, \mathbf{M}$ - tail tip of fourth-stage larva, lateral and ventral views; $\mathbf{N}$ - tail tip of specimen undergoing last (fourth) moult, ventral view; $\mathbf{O}$ - tail of female fourth-stage larva, lateral view; $\mathbf{P}$ - tail of male fourth-stage larva, lateral view. Scale bars: A, B, G-I, O, P = $100 \mu \mathrm{m} ; \mathrm{C}-\mathrm{F}=300 \mu \mathrm{m} ; \mathrm{J}, \mathrm{K}=50 \mu \mathrm{m} ; \mathrm{L}-\mathrm{N}=20 \mu \mathrm{m}$. 

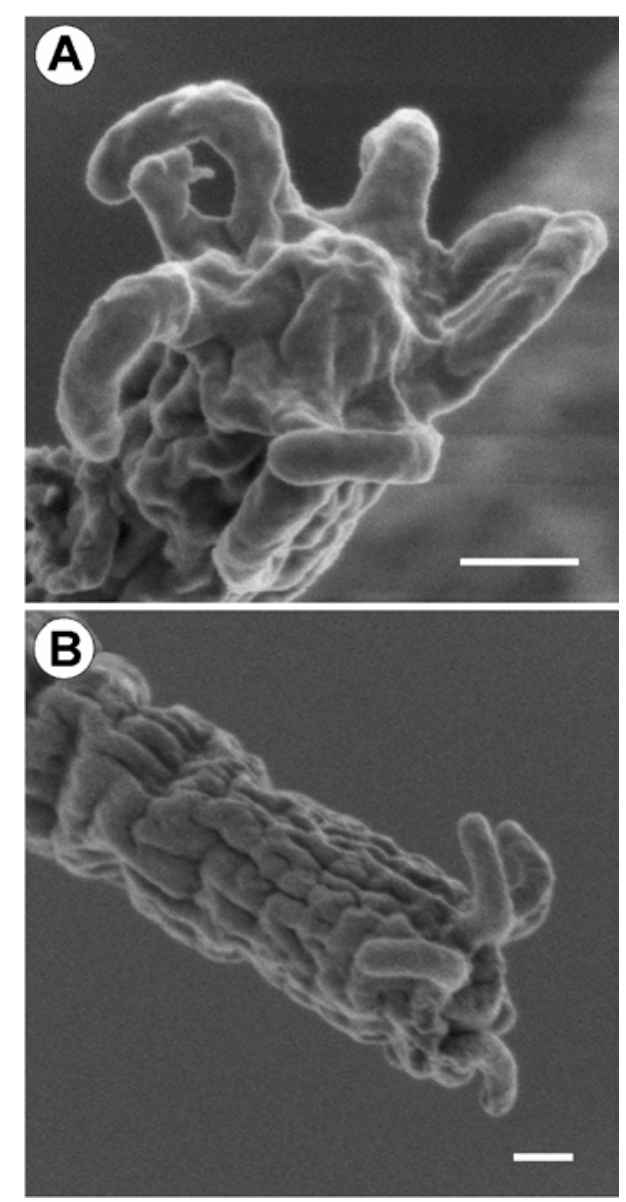

Fig. 5. Camallanus cotti Fujita, 1927, scanning electron micrographs of the tail end of the first-stage larva. A, B - subapical and lateral views, respectively. Scale bars: A, B $=100$ nm.

coil and discoil their bodies, attracting thus by these movements the copepod intermediate hosts. The presence/absence and the character of caudal processes in first-stage larvae might be an important taxonomic feature for different Camallanus spp.

The fourth-stage larva of $C$. cotti was described from experimentally infected fishes by Levsen and Berland (2002a). They reported only two mucrons on the tail tip of this larval stage, but there were always three small spikes or mucrons present in the fourth-stage larvae of C. cotti from both Canada (Fig. $4 \mathrm{~L}-\mathrm{N}$ ) and New Caledonia (Fig. $3 \mathrm{C}$ ), of which the dorsal one was larger than both subventral. In having three caudal spikes, $C$. cotti fourth-stage larvae resemble those of other Camallanus spp. [e.g., C. carangis Olsen, 1952, C. lacustris, C. oxycephalus, C. truncatus (Rudolphi, 1814) - see Moravec 1969, 1971, Stromberg and Crites 1974, Moravec et al. 2006b]. The buccal capsule of $C$. cotti fourth-stage larvae is similar to that in adults, but the tridents are absent. The fourth-stage larva of $C$. carangis, a species parasitizing marine fishes, has recently been found to have the buccal capsule provided with two sclerotized rod-like structures (Moravec et al. 2006b); these are,

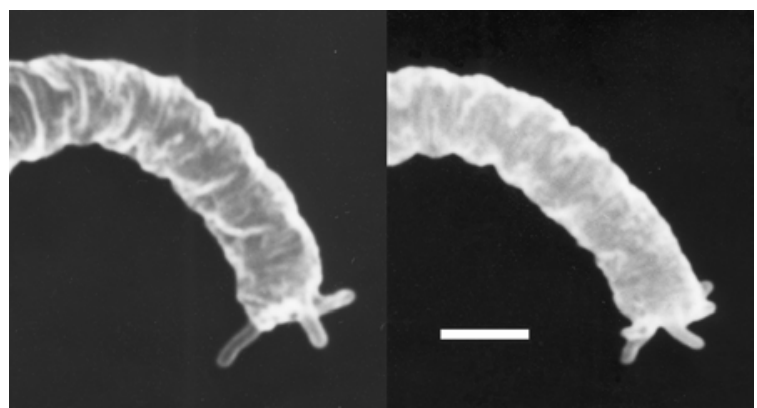

Fig. 6. Camallanus lacustris (Zoega, 1776), scanning electron micrographs of the tail end of the first-stage larva (specimens from Perca fluviatilis of the Mácha Lake fishpond system, Czech Republic, collected in June 1997). Scale bar $=1 \mu \mathrm{m}$.

however, absent from the capsule of the larvae of $C$. cotti, by which this species resembles some other $\mathrm{Ca}$ mallanus spp. (C. lacustris, C. oxycephalus, C. truncatus).

A characteristic feature of $C$. cotti is the unusually long tail of the gravid female, which is an important taxonomic feature distinguishing $C$. cotti from most other congeneric species (Moravec 1973). Fig. 3 N shows that the three small caudal spikes, which are present in fourth-stage larvae, are lost during the last (fourth) moult. However, a considerable increase in tail length occurs after the moult (Fig. $3 \mathrm{C}-\mathrm{F}$ ), along with the body growth and development of female reproductive organs, as also demonstrated by Levsen and Berland 2002b). Therefore, only gravid (i.e., larvigerous) females of Camallanus spp. should be compared, as it is used in philometrid nematodes (Moravec 2004). By the conspicuously long tail in gravid female, $C$. cotti resembles $C$. oxycephalus from North American fishes and $C$. kirandensis Baylis, 1928 and C. longicaudatus Moravec, 1973 from cyprinids in Africa; however, these are distinctly larger than $C$. cotti and differ in some other characters.

Camallanus cotti was originally described by Fujita (1927a,b) from four fish species of Lake Biwa and Lake Tazawa in Japan; later Yamaguti $(1935,1941)$ and Moravec and Nagasawa (1989) redescribed it from the specimens newly collected from different Japanese fishes. Moravec (1973) and Moravec and Sey (1988) synonymized Camallanus zacconis Li, 1941 and $C$. fotedari Raina et Dhar, 1972, two species described from Korea and India, respectively (Li 1941, Raina and Dhar 1972), with C. cotti. However, it is necessary to synonymize also Camallanus moraveci Petter, Cassone et France, 1974 described from Mollienesia latipinna [= Poecilia latipinna (Lesueur)] and Xiphophorus helleri Heckel imported from Singapore to France (Petter et al. 1974). This species should differ from $C$. cotti only in the allegedly absence of the left spicule; however, the left spicule is always present in Camallanus spp., but due to its poor sclerotization and a certain intraspecific variability, sometimes this spicule may seem to be ab- 
sent (see Moravec et al. 2006b). On the other hand, the hosts of $C$. moraveci belong to the most frequently recorded hosts of $C$. cotti in aquarium conditions worldwide. Probably identical with $C$. cotti is also Camallanus maculatus Martins, Piazza et Garcia, 2004 reported from aquarium-reared Xiphophorus maculatus (Günther) in Brazil (Martins et al. 2004), but since this species has not yet been formally described (per. comm. of M.L. Martins), C. maculatus should be considered a nomen nudum.

Camallanus cotti has been reported from a number of fish species belonging to different families and orders. It seems it was originally distributed in eastern, southeastern and southern Asia, from where it has been recorded from Japan, China, eastern Russia (Amur R. basin), Korea, Vietnam, Singapore and India (e.g., Fujita 1927a,b, Yamaguti 1935, 1941, Li 1941, Dogiel and Akhmerov 1959, Roytman 1963, Raina and Dhar 1972, Chen 1973, Petter et al. 1974, Wang et al. 1979, 1997, Wu 1984, Vismanis et al. 1987, Moravec and Sey 1988, Moravec and Nagasawa 1989, Wu et al. 1991, Kim et al. 2002, Moravec et al. 2003). It also occurs in the cultures of aquarium fishes in Europe, North America (Canada), South America (Brazil), West Indies (Puerto Rico) and Australia, where this pathogenic parasite is being brought in along with exotic fishes, imported mainly from Singapore (e.g., Schubert 1972, Petter et al. 1974, Stumpp 1975, Campana-Rouget et al. 1976, Bunkley-Williams and Williams 1994, Font and Tate 1994, Alves et al. 2000, Evans and Lester 2001, Levsen 2001, Levsen and Berland 2002a,b, Levsen and Jakobsen 2002, Menezes et al. 2006). Camallanus cotti has also been reported from native and introduced fishes in some streams in Hawaii, where it was apparently brought in along with the introduction of poeciliids (Font and Tate 1994, Font 1997a, b, 1998, 2003, Vincent and Font 2003a, b).

In New Caledonia (La Foa River), adults and a few larvae of $C$. cotti were recorded only from the gobiid Awaous guamensis, with a relatively high prevalence (51\%) and intensity (up to 25 ), whereas only a single fourth-stage larva was found in the dark-margined flagtail Kuhlia marginata. Other native fishes examined, including gobiids ( $R$. bikolanus and S. lagocephalus) and another Kuhlia species, as well as the introduced fishes, were not infected (see the list in Material and Methods). It is remarkable that neither the introduced Xiphophorus helleri was infected, which is one of the most frequently reported hosts of $C$. cotti in aquarium cultures and in the streams in Hawaii (Rigby et al. 1997, Vincent and Font 2003a); but only three specimens of this fish were examined. Awaous guamensis, a species widespread in Oceania (Froese and Pauly 2006), was found to be infected with C. cotti also in Hawaii (Rigby et al. 1997, Font 2003). It is highly probable that, similarly as in Hawaii, C. cotti was introduced into New Caledonia along with infected poeciliids. This is the first record of $C$. cotti from New Caledonia and its finding in Kuhlia marginata represents the first host record. It can be expected that more New Caledonian fish species will be found as hosts of this nematode parasite.

The host specificity of $C$. cotti is low and, as far as we could find, it has been recorded from the following fish species $\left({ }^{\mathrm{a}}=\right.$ in aquarium culture, ${ }^{\mathrm{b}}=$ an introduced species; ${ }^{\mathrm{c}}=$ an autochtonous species parasitized with the introduced $C$. cotti ${ }^{\mathrm{d}}=$ in both natural waters and aquarium culture): Rajiformes: Potamotrygonidae: ${ }^{\mathrm{a}}$ Potamotrygon sp.; Acipenseriformes: Acipenseridae: Huso dauricus (Georgi); Cypriniformes: Balitoridae: Triplophysa kashmirensis (Hora); Cobitidae: ${ }^{\mathrm{a} C h r o m o b o t i a}$ macracanthus (Bleeker), ${ }^{\mathrm{d}}$ Misgurnus anguillicaudatus (Cantor); Cyprinidae: Acanthorhodeus asmussii (Dybowski), Acheilognathus taenianalis (Günther), Culter erythropterus Basilewsky, Culter mongolicus Basilewsky, ${ }^{a}$ Danio rerio (Hamilton), Elopichthys bambusa (Richardson), Gobio cynocephalus Dybowski, Hemibarbus labeo (Pallas), Hemiculter leucisculus (Basilewsky), Leuciscus waleckii (Dybowski), Megalobrama terminalis (Richardson), Ochetobius elongatus (Kner), Opsariichthys uncirostris (Temminck et Schlegel), Parabramis pekinensis (Basilewsky), Phoxinus lagowskii Dybowski, Pseudaspius leptocephalus (Pallas), Squaliobarbus curriculus (Richardson), Tribolodon hakonensis (Günther), Zacco platypus (Temminck et Schlegel), Zacco temmincki (Temminck et Schlegel); Siluriformes: Bagridae: Pelteobagrus fulvidraco (Richardson); Callichthyidae: ${ }^{\mathrm{a}}$ Corydoras sp.; Siluridae: Parasilurus asotus (Linnaeus) (type host); Sisoridae: Bagarius bagarius (Hamilton); Salmoniformes: Salmonidae: Oncorhynchus masou (Brevoort); Cyprinodontiformes: Aplocheilidae: ${ }^{\mathrm{a}}$ Fundulopanchax gardneri (Boulenger); Poeciliidae: ${ }^{\mathrm{b}}$ Gambusia affinis (Baird et Girard), ${ }^{\mathrm{b}}$ Poecilia mexicana Steindachner, ${ }^{\mathrm{a}, \mathrm{b}}$ Poecilia reticulata Peters, ${ }^{\mathrm{a}, \mathrm{b}}$ Xiphophorus helleri Heckel, ${ }^{\mathrm{a}}$ Xiphophorus maculatus (Günther); Scorpaeniformes: Cottidae: Cottus pollux (Günther), Cottus reinii Hilgendorf, Mesocottus haitej (Dybowski); Perciformes: Channidae: Channa argus (Cantor); Cichlidae: ${ }^{\mathrm{a}}$ Geophagus surinamensis

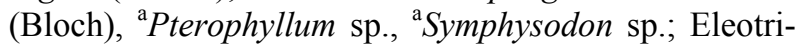
dae: ${ }^{\mathrm{c}}$ Eleotris sandwicensis Vaillant et Sauvage; Gobiidae: ${ }^{\mathrm{c}}$ Awaous guamensis (Valenciennes), Chaenogobius macrognathos (Bleeker), ${ }^{\mathrm{c}}$ Lentipes concolor (Gill), Rhinogobius lindbergi Berg, Rhinogobius similis Gill, ${ }^{\mathrm{c}}$ Stenogobius hawaiiensis Watson; Kuhliidae: ${ }^{\mathrm{c}}$ Kuhlia marginata (Cuvier); Odontobutidae: Odontobutis obscura (Temminck et Schlegel), Percottus glenii Dybowski; Osphronemidae: a Betta splendens Regan, Macropodus chinensis (Linnaeus), ' Macropodus opercularis (Linnaeus); Percichthyidae: Siniperca chuatsi (Basilewsky); Percidae: ${ }^{\mathrm{b}}$ Perca fluviatilis Linnaeus.

As in other members of the Camallanidae, the life cycle of $C$. cotti involves a copepod intermediate host; Cyclops sp., Macrocyclops albidus (Jurine) and Mesocyclops leuckarti (Claus) were found to serve as its suit- 
able experimental intermediate hosts (Wang and Ling 1975, Campana-Rouget et al. 1976, Levsen and Berland 2002a, b). Some authors (Stumpp 1975, Levsen 2001, Levsen and Jakobsen 2002) consider this species to be also capable of a direct (monoxenous) development. However, results of the experiments performed by Levsen and Jakobsen (2002) to prove this are not quite conclusive and the presumed monoxenous development of $C$. cotti would need a reliable verification.

Acknowledgements. The authors wish to thank Dr. Christine Pöllabauer (Erbio, Nouméa, New Caledonia) for organizing an electrofishing expedition to the La Foa River, her collaboration, fish identification and fruitful discussions. Eric Bureau, a student, participated in the fishing expedition and parasitological examination of fish. Angelo Di Matteo (IRD, Nou- méa) is thanked for technical help. Drs. Norbert P. Boyce and late Leo Margolis (Pacific Biological Station, Nanaimo, British Columbia) kindly provided specimens of $C$. cotti from aquarium-kept Misgurnus anguillicaudatus and laboratory facilities during the senior author's stay in Canada in 1979. Thanks are also due to the staff of the Laboratory of Electron Microscopy of the Institute of Parasitology, ASCR, in České Budějovice for their technical assistance and Irena Husáková from the Department of Helminthology of the same Institute for her help with the preparation of illustrations. Voucher specimens of Camallanus cotti from Hawaii were kindly lent by Dr. Patricia Pilitt, US National Parasite Collection, Beltsville, Maryland, USA. This study was partly supported by grant no. 524/06/0170 from the Grant Agency of the Czech Republic and by the research projects of the Institute of Parasitology, ASCR (Z60220518 and LC522).

\section{REFERENCES}

ALVES D.R., LUQUE J.L., PARAGUASSÚ A.R., MARQUES F.A. 2000: Ocorrência de Camallanus cotti (Nematoda: Camallanidae) parasitando o guppy Poecilia reticulata (Osteichthyes: Poeciliidae) no Brasil. Rev. Univ. Rural, Ser. Ci. Vida, 22: 77-79.

BUNKLEY-WILLIAMS L., WILLIAMS E.H. 1994: Parasites of Puerto Rican Freshwater Sport Fishes. Puerto Rico Department of Natural and Environmental Resources, San Juan, PR and Department of Marine Sciences, University of Puerto Rico, Mayagüez, PR, 164 pp.

CAMPANA-ROUGET Y., PETTER A.-J., KREMER M., MOLET B., MILTGEN F. 1976: Présence du nématode Camallanus fotedari dans le tube digestif de poissons d'aquarium de diverses provenances. Bull. Acad. Vét. Fr. 49: 205-210.

CHEN C. (Ed.) 1973: [An Illustrated Guide to the Fish Diseases and Causative Pathogenic Fauna and Flora in the Hubei Province.] Science Press, Beijing, 456 pp. (In Chinese.)

DOGIEL V.A., AKHMEROV A.Kh. 1959: [Nematodes of fishes of the River Amur.] Acta Hydrobiol. Sin. 3: 272 304. (In Chinese and Russian.)

EVANS B.B., LESTER R.J.G. 2001: Parasites of ornamental fish imported into Australia. Bull. Eur. Assoc. Fish Pathol. 21: $51-55$.

FONT W.F. 1997a: Distribution of helminth parasites of native and introduced stream fishes in Hawaii. Bishop Museum Occasional Papers, Records of the Hawaii Biological Survey for 1996, Part 2, Notes 49: 56-62.

FONT W.F. 1997b: Improbable colonists: Helminth parasites of freshwater fishes on an oceanic island. Micronesica 30: $105-115$.

FONT W.F. 1998: Parasites in paradise: patterns of helminth distribution in Hawaiian stream fishes. J. Helminthol. 72: 307-311.

FONT W.F. 2003: The global spread of parasites: What do Hawaiian streams tell us? BioScience 53: 1061-1067.

FONT W.F., TATE D.C. 1994: Helminth parasites of native Hawaiian freshwater fishes: an example of extreme ecological isolation. J. Parasitol. 80: 682-688.
FROESE R., PAULY D. (Eds.) 2006: FishBase. World Wide Web electronic publication, www.fishbase.org, version 05/2006.

FUJITA T. 1927a: [Parasitic nematodes of fish from Lake Biwa.] Dobutsugaku Zasshi 39: 39-45 + Pl. I. (In Japanese.)

FUJITA T. 1927b: On new species of nematodes from fishes of Lake Biwa. Jpn. J. Zool. 1: 169-176.

GARGOMINY O., BOUCHET P., PASCAL M., JAFFRÉ T., TOURNEUR J.-C. 1996: Conséquences des introductions d'espèces animales et végétales sur la biodiversité en Nouvelle-Calédonie. Rev. Écol. (Terre et Vie) 51: 375 402.

KELLY R., CRITES J.L., MERGO J.C. 1989: Comparative morphology of the first-stage larvae of two species of Philometra (Nematoda: Philometridae) and one species of Camallanus (Nematoda: Camallanidae) from Lake Erie fishes. Ohio J. Sci. 89: 70-73.

KIM J.-H. 2002: Nematode worm infections (Camallanus cotti, Camallanidae) in guppies (Poecilia reticulata) imported to Korea. Aquaculture 205: 231-235.

LEVSEN A. 2001: Transmission ecology and larval behaviour of Camallanus cotti (Nematoda, Camallanidae) under aquarium conditions. Aquarium Sci. Conserv. 3: 315-325.

LEVSEN A. BERLAND B. 2002a: The development and morphogenesis of Camallanus cotti Fujita, 1927 (Nematoda: Camallanidae), with notes on its phylogeny and definitive host range. Syst. Parasitol. 53: 29-37.

LEVSEN A., BERLAND B. 2002b: Post-embryonic development of Camallanus cotti (Nematoda: Camallanidae), with emphasis on growth of some taxonomically important somatic characters. Folia Parasitol. 49: 231-238.

LEVSEN A., JAKOBSEN P.J. 2002: Selection pressure towards monoxeny in Camallanus cotti (Nematoda, Camallanidae) facing an intermediate host bottleneck situation. Parasitology 124: 625-629.

LI S.Y. 1941: On two new species of nematodes from China. Peking Nat. Hist. Bull. 15: 195-199.

MARQUET G., KEITH P., VIGNEUX E. 2003: Atlas de Poissons et des Crustacés (Décapodes) d'Eau Douce de Nouvelle-Calédonie. Publications Scientifiques du Mu- 
séum National d'Histoire Naturelle, Paris, Patrimoines Naturels 58: 1-282.

MARTINS M.L., PIAZZA R.S., GARCIA F. 2004: Camallanus maculatus (Nematoda: Camallanidae) em peixe ornamental, Xiphophorus maculatus (Osteichthyes: Poeciliidae) cultivado no Estado de São Paulo. In: VIII ENBRAPOA - Encontro Brasileiro de Patologistas de Organismos Aquáticos, 2004, Laguna, 19-22 outubro. VIII ENBRAPOA - resumos, 2004, p. 20.

MENEZES R.C., TORTELLY R., TORTELLY-NETO R., NORONHA D., PINTO R.M. 2006: Camallanus cotti Fujita, 1927 (Nematoda, Camallanoidea) in ornamental aquarium fishes: pathology and morphology. Mem. Inst. Oswaldo Cruz 101: 683-687.

MORAVEC F. 1969: Observations on the development of Camallanus lacustris (Zoega, 1776) (Nematoda: Camallanidae). Acta Soc. Zool. Bohemoslov. 33: 15-33.

MORAVEC F., 1971: Some notes on the larval stages of Camallanus truncatus (Rudolphi, 1814) and Camallanus lacustris (Zoega, 1776) (Nematoda: Camallanidae). Helminthologia 10 (Year 1969): 129-135.

MORAVEC F. 1973: On the nematode Camallanus longicaudatus sp. n. from the Nile fish, Labeo horie Heck. Rev. Zool. Bot. Afr. 87: 165-173.

MORAVEC F. 2004: Some aspects of the taxonomy and biology of dracunculoid nematodes parasitic in fishes: a review. Folia Parasitol. 51: 1-13.

MORAVEC F., JUSTINE J.-L., RIGBY M.C. 2006b: Some camallanid nematodes from marine perciform fishes off New Caledonia. Folia Parasitol. 53: 223-239.

MORAVEC F., JUSTINE J.-L., WÜRTZ J., TARASCHEWSKI H., SASAL P. 2006a: A new species of Procamallanus (Nematoda: Camallanidae) from Pacific eels (Anguilla spp.). J. Parasitol. 92: 130-137.

MORAVEC F., NAGASAWA K. 1989: Observations on some nematodes parasitic in Japanese freshwater fishes. Folia Parasitol. 36: 127-141.

MORAVEC F., NIE P., WANG G. 2003: Some nematodes of fishes from central China, with the redescription of Procamallanus (Spirocamallanus) fulvidraconis (Camallanidae). Folia Parasitol. 50: 220-230.

MORAVEC F., SEY O. 1988: Nematodes of freshwater fishes from North Vietnam. Part 1. Camallanoidea and Habronematoidea. Acta Soc. Zool. Bohemoslov. 52: 128-148.

PETTER A.-J., CASSONE J., FRANCE B.-M. 1974: Un nouveau nématode Camallanus pathogène dans des élevages de poissons exotiques. Ann. Parasitol. Hum. Comp. 49: 677-683.

RAINA M.K., DHAR R.L. 1972: On Camallanus fotedari n. sp. (Nematoda: Spiruridea) from the intestine of Nemachilus kashmirensis in Kashmir, India. J. Helminthol. 46: 157-160.

RIGBY M.C., FONT W.F., DEARDORFF T.L. 1997: Redescription of Camallanus cotti Fujita, 1927 (Nematoda: Camallanidae) from Hawai'i. J. Parasitol. 83: 1161-1164.
ROYTMAN V.A. 1963: [Nematodes of fishes of the Zeya River basin.] Trudy GELAN 13: 253-300. (In Russian.)

SCHUBERT G. 1972: A new fish enemy. Trop. Fish Hobbyist 21: $15-20$.

STROMBERG P.C., CRITES J.L. 1974: The life cycle and development of Camallanus oxycephalus Ward and Magath, 1916 (Nematoda: Camallanidae). J. Parasitol. 60: 117-124.

STUMPP M. 1975: Untersuchungen zur Morphologie und Biologie von Camallanus cotti (Fujita, 1927) [sic]. Z. Parasitenkd. 46: 277-290.

VINCENT A.G., FONT W.F. 2003a: Host specificity and population structure of two exotic helminths, Camallanus cotti (Nematoda) and Bothriocephalus acheilognathi (Cestoda), parasitizing exotic fishes in Waianu Stream, O'ahu, Hawai'i. J. Parasitol. 89: 540-544.

VINCENT A.G., FONT W.F. 2003b: Seasonal and yearly population dynamics of two exotic helminths, Camallanus cotti (Nematoda) and Bothriocephalus acheilognathi (Cestoda), parasitizing exotic fishes in Waianu Stream, O'ahu, Hawaii. J. Parasitol. 89: 756-760.

VISMANIS K.O., LOMAKIN V.V., ROYTMAN V.D., SEMENOVA M.K., TROFIMENKO V.Ya. 1987: Nemathelminths - Nemathelminthes. In: O.N. Bauer (Ed.), [Key to Parasites of Freshwater Fishes of the USSR Fauna. Vol. 3. Parasitic Metazoans, Part 2.] Nauka, Leningrad, pp. 199-310. (In Russian.)

WANG P., LING X. 1975: Some nematodes of the suborder Camallanata from Fujian Province, with notes on their life histories. Acta Zool. Sin. 21: 350-358. (In Chinese, Engl. summary.)

WANG P., ZHAO Y., WANG X., ZHANG J. 1979: Report on some nematodes from vertebrate animals in Central and South China. Fujian Shida Xuebao 2: 78-92. (In Chinese, Engl. summary.)

WANG W., LI L., YU Y., FENG W., XIAO C., WANG G., LIU J., YAO W., FENG S. 1997: Parasitic fauna of fishes in Wuling Mountains area. In: D. Song (Ed.), [Invertebrates of Wuling Mountains Area, Southwestern China.] Science Press, Beijing, pp. 73-146. (In Chinese, Engl. summary.)

WU H. 1984: [The parasitic nematodes of fishes from Liao He in China.] In: [Parasitic Organisms of Freshwater Fish of China.] Agricultural Publishing House, Beijing, pp. 177200. (In Chinese.)

WU H., LI L., FENG W., YAO W., LIU J., YU Y. 1991: [A preliminary study on the fish parasitic fauna of the Bao'an Lake.] In: C. Hu, X. Huang (Eds.), [Collected Papers on the Fishery Ecology and Exploitation Technology of Bao'an Lake.] Science Press, Beijing, pp. 160-171. (In Chinese.)

YAMAGUTI S. 1935: Studies on the helminth fauna of Japan. Part 9. Nematodes of fishes, 1. Jpn. J. Zool. 6: 337-386.

YAMAGUTI S. 1941: Studies on the helminth fauna of Japan. Part 33. II. Nematodes of fishes. Jpn. J. Zool. 9: 343-396. 